\title{
Use of a blog as a tracking tool for student-supervisor interaction in a Biomedical Informatics course: Future portfolios
}

\author{
Dr. M. R. Sheriff MBBS, MSc \\ Senior Medical Officer, Western Hospital, Colombo, Sri Lanka \\ E-Mail address: rikaz.sheriff@gmail.com
}

\section{Prof. J. U. Weerasinghe BDS, MS, PhD}

Professor in Oral and Maxillofacial Surgery, Faculty of Dental Sciences, University of Peradeniya, Peradeniya, Sri Lanka

E-Mail address: juw@pdn.ac.lk

Dr. G. Ponnamperuma MBBS, Dip. Psychology, MMEd, PhD

Lecturer, Medical Education Development and Research Centre, Faculty of Medicine, University of Colombo, Sri Lanka

E-Mail address: gomindap@ hotmail.com

Sri Lanka Journal of Bio-Medical Informatics 2012;3(3):101-105

doi: http://dx.doi.org/10.4038/sljbmi.v3i3.3779

\begin{abstract}
A blog can be considered as a diary of online thoughts. Derived from the term web log, blog is a method of posting entries to a specific URL. Initially used for text entry, blogs have now evolved into interactive and multimedia rich posts of information which can be maintained using various devices.

While the existing methods of communication between the student and the supervisor such as official letters, telephone conversations, face to face meetings, and online meetings are being practiced there are problems of using these multiple methods over a longer period of time because of the difficulties in maintaining a chronological order, cataloguing minutes of meetings and excess paperwork. It may question the supervisory role of consultants and address the affective domain of learning. Blogs seem to give significant advantages in organising activities of a research project as well as aid in reflective learning. A survey of scientific literature shows active use of blogs in both medical teaching and training and as an aid to reflective learning.
\end{abstract}

A blog was maintained for 40 weeks between September 2010 and July 2011 by a student of the MSc in Biomedical Informatics course which was overseen by two supervisors. In the course of maintaining a blog, its use as a tracking tool and reflective learning medium was evident.

It can then be concluded that a blog can be seen as a useful aide in tracking student progress in a Biomedical Informatics course and has potential to be used in other medical disciplines as an adjunct to portfolio.

Keywords - Blog; Biomedical Informatics; Portfolio; Medical Education Informatics

\section{Introduction}

When a postgraduate student is about to embark on a research project in order to write the dissertation, it is necessary to have regular meetings with supervisors to decide on the design, implementation and writing of the dissertation. These include writing a comprehensive literature review, methodology, analysis of results, discussion and conclusions. All these sections need to be closely studied by the supervisor who has to advice the student on the necessary modifications and track the progress at regular intervals.

Current methods of student-supervisor communication during the research project include letters (postal or e-mail), face-to-face meetings, telephone conversations and online meetings. 
Letters may take a long time to reach and telephone conversations, face-to-face meetings and

online meetings require both parties to be available simultaneously which may not be practical for consultants or supervisors. E-mails may be useful in exchanging electronic documents but usage of common e-mail boxes may carry the risk of not getting adequate attention.

These conventional methods have inherent problems in postgraduate supervision listed below:

- Difficulty in maintaining a chronological order of encounters

- Multiple modes of communication confuses instructions. Ideas may be repeated after a period of time and there is no way to check if a specific technique was used previously

- Difficulty in cataloguing minutes of meetings

- Any meeting with a supervisor can bring out an important point but mostly there is no proper method to minute this for future reference

- Consultants may find it difficult to carry out supervisory roles

- Multitasking as a supervisor may lead to a quality drop in their research activities.

- Excessive paperwork and checking

- Failure to monitor the research project periodically, results in having to check a large quantity of paperwork at the final phase of the thesis

- Effective domain of learning in thesis planning and writing cannot be addressed

- With meetings being generally few, supervisors find it difficult to gage if the student has. the right attitude and approach towards the dissertation (although the text in the thesis may be correct)

Maintaining a dedicated blog by the student to be accessed by the supervisor may be the answer to this problem.

Blogging began as a method of maintaining an online diary in $1994^{(1)}$. Whilst early blogs were simply text, modern blogging has many tools and blog posts in reverse chronological sequence, have resulted in rich creativity. Blogs can be hosted by dedicated blog hosting services or they can be run using blog software, or on regular web hosting services. The collective community of blogs is termed a 'Blogosphere'.

Blogs can come in many formats depending on the requirement of the user:

- Blog - Original web logs (eg. Blogger, Wordpress) which are predominantly textual in nature with elements of multimedia (eg. images)

- Linklog - A collection of links posted in chronological order (eg. Howl, DEL.ICIO.US).

- Photoblog - A collection published images in chronological order with elements of text (eg. Flickr, Fotolog).

- Vlog - A collections of predominantly video entries of a person/organisation (eg. YouTube, Vlogblog.com).

- Moblog - A term for a user / organisation which maintains a blog via mobile device.

\section{Use of blogs for postgraduate supervision}

Taking up the challenge of blogging and creating a hospitable environment to track a thesis is no easy task but will be a pleasant experience. Blogs have been used by the medical 
community as a training tool in undergraduate and postgraduate teaching. There are instances of blogs being used by medical personnel and organisations to either document events or impart knowledge ${ }^{(2)}$. Blogs have also been shown to be effective in traditional essay writing ${ }^{(3)}$. Blogs have been used as reflective $\operatorname{logs}{ }^{(4)}$. There have also been instances of blogs being used by postgraduate doctors as a teaching / learning tool ${ }^{(5)}$. Blogs allow expression of the feelings of the blogger ${ }^{(6)}$ and this allows the supervisors to address the mental challenges.

\section{Commonly used blogs}

Listed below are some common online blog publishing services. "Blogger" is the most popular and user friendly blog at present

- http://www.blogger.com/

- http://wordpress.org/

- http://movabletype.com/

- http://www.livejournal.com/

- https://posterous.com/

\section{Report on ten months of experience of using a blog for MSc Biomedical Informatics research project}

A blog (http://rikazbmiproject.blogspot.com) was maintained as an activity record keeping method by a student of the first batch of MSc in Biomedical Informatics assigned to two supervisors for the research project.

The blog was kept active for 10 months from the start of the research project. A total of 52 $\log$ entries were posted over the 40 week period. The blog's objectives were to track the progress of the research project, allow supervisors to monitor progress, develop an 'unofficial' portfolio of penned down thoughts to reflect on the student's approach, and to be used as a template for future students. In a period of 40 weeks the student and supervisors found the blog a useful tracking tool to monitor progress. There were periods of inactivity in the blog which corresponded to the student's inactivity which prompted the supervisor to take action.

The blog notes the state of the research project. In addition, anecdotes of activities (eg. facing a viva) were also posted. In this particular instance supervisors chose to read the blog and reply via e-mail.

The dynamics of approach and attitude to the project can be tracked in the blog posts. Changes in time and resources have prompted the student to alter the pattern of thinking and this change is visible when reading the whole content of the blog thus giving the supervisor a clue as to the level of reflective learning of the student, an often missed component in medical training ${ }^{(7)}$.

\section{Advantages and disadvantages of the use of a blog by students and supervisors}

\section{Advantages}

1. Meeting deadlines of a research project even multiple methods of communication when blogged on time, result in a chronological sequence of thoughts which could easily be referenced. 
2. Minutes of meetings can be recorded in an organised manner.

All meetings could be catalogued into the blog wherein important facts could reside to be used in the thesis.

3. Supervisory role could be carried out at the supervisor's pace.

Since supervisors are not required to have frequent face-to-face meetings, blogs have enabled them to be operational from a distance. Supervisors could now check the blog at anytime. This gives a better opportunity for organised thought, which may lead to a better product. Instead of going through numerous e-mails sent by students, the supervisors can log into track students' progress in the blog dedicated for the research project at their convenience. This will also reduce the accidental deletion of important e-mails from the student in the mailbox of the supervisor.

4. Paperwork and dissertation checking could be reduced.

Lack of paperwork has reduced the unnecessary printing cost and time wastage. Tracking a student via blogs allows the supervisor great insight into both content and methodology used by the student. A simple comment in a blog can easily guide the student. A supervisor and student having a good online rapport, and a good idea of the structure of the thesis will certainly reduce multiple thesis drafts and checks before the final submission.

5. Affective domain of learning can be addressed.

Supervisors can help students to solve issues at important milestones of writing a research thesis.

\section{Disadvantages}

1. Both students and supervisors should be ICT prepared.

The success of this system depends on the ICT preparedness of both parties while respecting each others' strengths and limitations.

2. Security issues.

Making web content available in the public domain may be considered a security risk.

\section{Future use of blogs as monitoring tools}

It is proposed that guidelines be set with both student and supervisor in operating such a blog.

\section{Students}

1. Maintain a minimum of one blog entry per week or as decided by the supervisor(s).

2. All correspondence with supervisors / stakeholders shall be maintained in the blog on time.

3. All blog entries should be clearly labeled reflecting the body of the post.

4. Maintain common courtesy.

5. It is an offense to entertain profanity in blogging.

6. Encourage student participation across blogs.

7. The student is totally responsible for all content posted on the blog.

\section{Supervisors}

1. Timely replies to encourage meeting deadlines.

2. Promote the use of the blog as the only means of recording of project activities. 
3. Supervisors can enlist the help required by the student for any blogging queries.

Therefore, it seems that blogs have indeed been successfully used in the past for both teaching and training in medical education predominantly for undergraduate students. It has also shown merit as a reflective teaching aid.

\section{Conclusion}

Modern blogs are both convenient and user friendly with mobile and SMS methods to maintain them. Problems of technical competency of student and supervisor, availability of resources (hardware, software, and internet), resistance to change can be seen as obstacles to its implementation. While further research is required, this case report has shed some positive light that such blogs may yield good results in other medical disciplines as it has shown in this MSc course.

\section{References}

1. Harmanci R. Time to get a life - pioneer blogger Justin Hall bows out at 31. San Francisco Chronicle. Available from: http://www.sfgate.com/cgibin/article.cgi?file=/c/a/2005/02/20/MNGBKBEJO01.DTL

2. Virdi J. History of Medicine Blogs. From the Hands of Quacks. Available from http://jaivirdi.wordpress.com/2010/06/13/history-of-medicine-blogs/

3. Fischer M, Haley H, Saarinen C, \& Chretien K. Comparison of blogged and written reflections in two medicine clerkships. Medical Education 2011; 45: 166-75 doi: http://dx.doi.org/10.1111/j.1365-2923.2010.03814.x.

4. Chretien K, Goldman E, Faselis C. The Reflective Writing Class Blog: Using Technology to Promote Reflection and Professional Development. Journal of General Internal Medicine 2008; 23: 2066-70.

doi: http://dx.doi.org/10.1007/s11606-008-0796-5.

5. Sethi K. Blog/Web Log-A New Easy and Interactive Website. Journal of Thoracic Imaging 2007; 22: 115-19.

doi: http://dx.doi.org/10.1097/01.rti.0000213578.47398.aa

6. Qian H, Scott CR. Anonymity and Self-Disclosure on Weblogs. Journal of ComputerMediated Communication, 12, article 14.

http://jcmc.indiana.edu/vol12/issue4/qian.html 